\title{
Etiological profile of upper airway obstruction in infants
}

\author{
Essam Abo Elmagd ${ }^{1}$, Bahaa El Hawary ${ }^{2}$, Megahed M. Hassan ${ }^{3^{*}}$ (D) Hanem Kassem ${ }^{1}$ and Abd El Rahman El Tahan ${ }^{1}$
}

\begin{abstract}
Background: Respiratory distress is recognized as any sign of breathing difficulty in infants. Some congenital anomalies present immediately with airway distress, while others are asymptomatic or discovered later in infancy or childhood. Our objectives are to detect different laryngeal causes of respiratory distress in infants and to measure the relative risk of some variables like age, sex, family history, and other congenital anomalies for developing laryngeal causes of respiratory distress. This observational cross-sectional study was carried out during the period from June 2017 to December 2018 at Children's University Hospital. The study included 80 infants who presented with respiratory distress and admitted to the hospital. All patients subjected to a detailed history from their parents and full general and ENT examinations. X-ray, MSCT neck or direct laryngoscope were carried out in selected cases.

Results: As regard age, 58\% of cases were between 1-6 months, 28\% of cases between 6 months and 1 year, and $14 \%$ between $1-2$ years. Laryngeal causes of respiratory distress among infants were distributed as follow: $70 \%$ laryngomalacia, $18 \%$ subglottic stenosis, $8 \%$ laryngeal web, and $4 \%$ of cases were caused by vocal fold paralysis (VFP). The laryngeal causes of respiratory distress did not reveal any statistically significant difference among different age groups or between both genders $(P=0.257,0.286$; respectively). Also, there was no statistically significant difference between infants with positive family history and those without as regard the laryngeal causes of respiratory distress $(P=.378)$.

Conclusion: The majority of respiratory distress cases (58\%) were between 1-6 months. Bivariant analysis of variables age, sex, family history, and other congenital anomalies showed that they were not potent risk factors for developing laryngomalacia, subglottic stenosis, laryngeal web, and vocal fold paralysis. Laryngomalacia represented the commonest cause of respiratory distress (70\%) followed by subglottic stenosis (18\%), then laryngeal web (8\%), and finally the vocal fold paralysis represented the least percentage (4\%). Apart from laryngomalacia, the percentages of other causes seem to vary according to sample size and geographic area of study. So, being familiar with the common causes of respiratory distress in a given region is very essential in order not to miss a potentially life-threatening diagnosis.
\end{abstract}

Keywords: Infants, Laryngeal, Respiratory distress, Laryngomalacia

\section{Background}

Respiratory distress is recognized as any sign of breathing difficulty in infants. It is a common problem in the early neonatal and infant period occurring in up to $7 \%$ of infants [1]. Stabilization of the infant and early

\footnotetext{
* Correspondence: megahed_hassan@med.sohag.edu.eg

${ }^{3}$ Phoniatrics Unit, Otolaryngology Department, Faculty of Medicine, Sohag University, Sohag, Egypt

Full list of author information is available at the end of the article
}

recognition of the etiology helps in minimizing complications and ensuring appropriate definitive therapy [2]. Stridor is a loud, harsh, and high-pitched respiratory sound. It is usually heard on inspiration due to partial obstruction of the airway (usually extra-thoracic - that is, in the trachea, larynx, or pharynx). Stridor can occur on expiration in severe upper airway obstruction but usually indicates tracheal or bronchial obstruction (intra-thoracic). Biphasic stridor suggests subglottic or tracheal 
obstruction [3]. Difficulties at the level of the larynx are commonly associated with stridor or noisy breathing. Some congenital anomalies present immediately with airway distress while others are asymptomatic or discovered later in infancy or childhood as feeding and growing difficulties [4]. Supraglottic anomalies including laryngomalacia, bifid epiglottis, saccular cyst, and laryngeal cleft affect the airway at the level of the epiglottis through the ventricle, which sits immediately superior to the vocal folds [5]. Laryngomalacia is the most common cause of stridor in newborns, affecting $45-75 \%$ of all infants with congenital stridor. Most infants with laryngomalacia will have mild symptoms and a benign disease course that resolves by the age of 12 to 24 months; however, it is important to recognize that not all cases of laryngomalacia have a benign course [6]. Glottic anomalies affect the airway involving the vocal folds and lead to a dysphonic or aphonic cry and may also present with stridor. It includes vocal fold paralysis (VFP) and laryngeal/ glottic web [7]. In the current research, we studied different causes of respiratory distress in a certain period of time to show the distribution of different causes of upper airway obstruction in infants and any possible risk factors. This is important to make otolaryngologists and pediatricians familiarize with every diagnosis and its possibility in our population in order to properly manage these potentially fatal conditions. Our objective in the current research is to reveal the etiological profile of respiratory distress in infants including possible relative risk of certain variables.

\section{Methods}

In this observational cross-sectional study, all methods and procedures were conducted in the period from June 2017 to December 2018 according to the Institutional Review Board of the Faculty of Medicine. Also, the study was approved by the Institutional Ethical Committee of the Faculty. Written informed consents were obtained from all parents. All patients were recruited from Children's University Hospital. This study included 80 infants (32 females and 48 males) with age range from 1 month to 2 years who presented in the study period. All included infants presented with respiratory distress. Patients with bronchial asthma or other chest diseases were excluded from the study. Detailed history taking was carried out including age, gender, family history of laryngeal congenital anomalies, and symptoms of respiratory distress (e.g., difficult breathing, grunting, and stridor). Careful general examination was done searching for any nasal flaring, cyanosis, respiratory rate, suprasternal, intercostal, and subcostal in-drawing. Also, full laryngeal examination was performed including laryngeal endoscopy by fiberoptic nasopharyngolaryngoscopy with HD headcam, Karl Stors tele pack X LED. In addition,
DL and radiological investigation (X-ray, multi-slice computer tomography (MSCT) for the neck) were carried out in selected cases. Moreover, every patient underwent complete blood count, serum calcium level, and random blood sugar. In this study, Monte Carlo exact $p$ test used as it is a statistical package for analyzing continuous or categorical data. The goal in the exact test is to enable researcher to make reliable interference when data are small, when requirement of each cell in data entry is less than 5 cases, so relying on the accuracy of exact $p$ value will be put in consideration during dealing with data of this study. Data were present blindly for the statistician to measure any association (relative risk) of some variables (age, sex, and family history) with laryngeal causes of respiratory distress.

\section{Results}

This study included 80 infants ( 32 females and 48 males) with age range from 1 month to 2 years. All cases were stable at the time of first diagnosis in the hospital with no definite cyanosis; however, they revealed some variable degrees of respiratory distress in the form of stridor and suprasternal in-drawing. All laboratory testing was normal. Following fiberoptic laryngoscopy, radiography confirmed diagnosis of subglottic stenosis (14 subjects) and laryngeal web (6 subjects) and excluded any anatomical abnormalities in the trachea. In subglottic stenosis, a narrowing of the subglottic airway in the region of cricoid cartilage was detected by a fiberoptic laryngoscope which is more sensitive than CT by showing small stenosis. Similarly, in laryngeal web, a membrane was seen to extend between the two vocal folds and partially occluded the glottis. These membranes have different thickness and vertical locations. It may be thin or thick and glottic, supraglottic, or subglottic. For the diagnosis of laryngomalacia, the endoscopic findings are retroverted, curled or omega-shaped epiglottis, and soft laryngeal structure with sucked-in aryepiglottic folds during inspiration resulting in laryngeal inlet closure. The vocal fold paralysis represents a challenging diagnosis in our infants because of continuous crying. However, the examiner must concentrate at the end of the cry when the infant takes inspiration to detect if one vocal fold abducts and the other is fixed. Sometimes, the entire vocal fold could not be seen, in this case fixed arytenoid on the affected is enough for the diagnosis especially when the infant has a weak hoarse cry. Bilateral vocal fold paralysis not included in our study. Figure 1 shows an example picture for each diagnosis. Figure 2 illustrates the distribution of different laryngeal causes of respiratory distress in infants. There was no statistical significance difference in age groups between laryngeal causes of respiratory distress $(\mathrm{MCP}=0.257)$ according to the Mont Carlo exact test (Table 1). For laryngomalacia, there are 

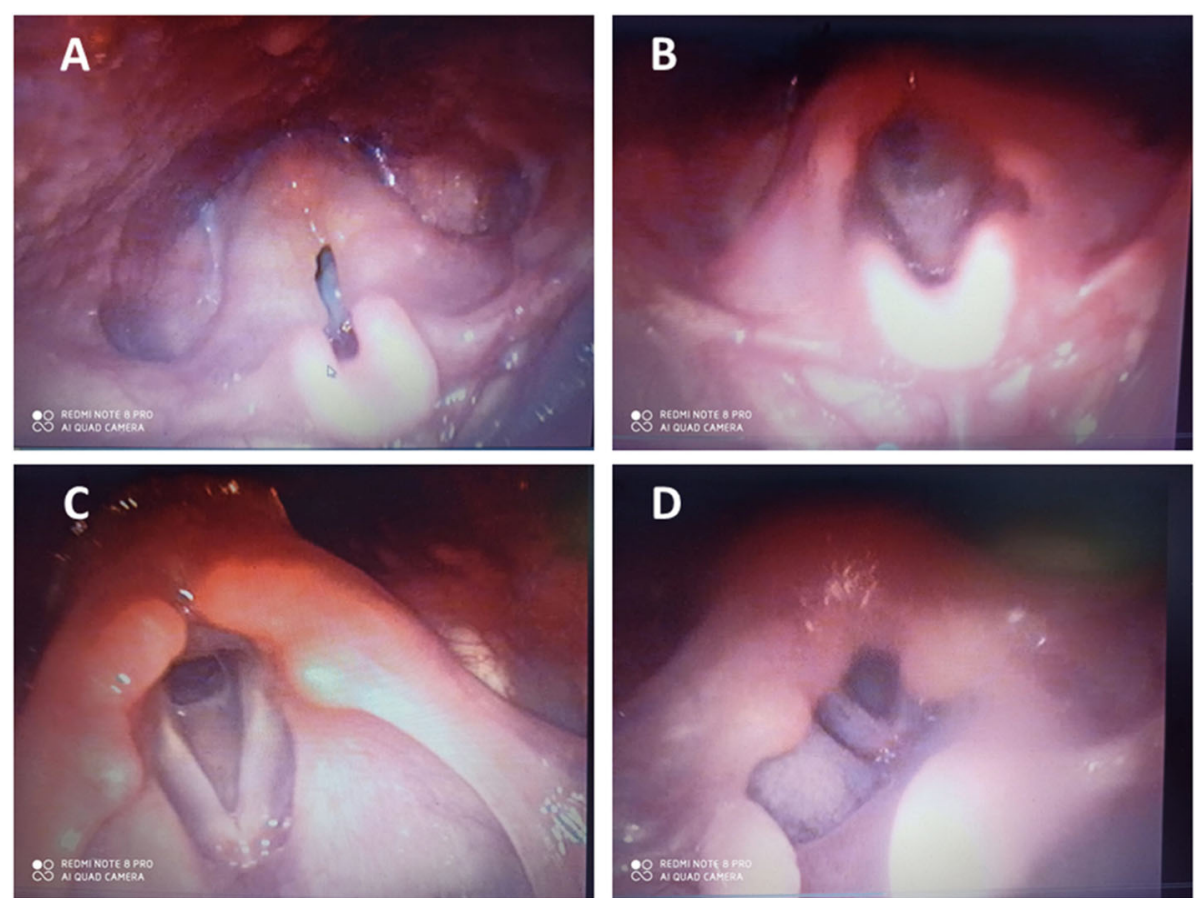

Fig. 1 Causes of respiratory distress. $\mathbf{a}$ is showing laryngomalacia with curled epiglottis and sucked-in aryepiglottic folds. $\mathbf{b}$ is showing subglottic stenosis with airway narrowing at the cricoid region. Note that some whitish secretion appears above the stenosis which may be mistaken for laryngeal web. $\mathbf{c}$ is showing the thin subglottic laryngeal web extending from the undersurface of both vocal folds. Lastly, $\mathbf{d}$ is showing left vocal fold paralysis with limited vocal fold mobility in abduction

36 cases in the infant age group 1-6 months, 16 cases in the infant age group 6 months to 1 year, and 4 cases from the age group 1 year-2 years. For subglottic stenosis, there are 7 cases from the age group 1 year to 2 years followed by 5 cases in infants aged 6 months to 1 year then only 2 cases in infants aged 1-6 months. All cases (6 cases) who suffered from laryngeal web were recorded in infants aged 1-6 months, while 2 cases of vocal fold paralysis were recorded from the age group 1-6 months and 2 cases from the age group 6 months to 1 year. Moreover, there was no statistically significant difference in the male and female groups between

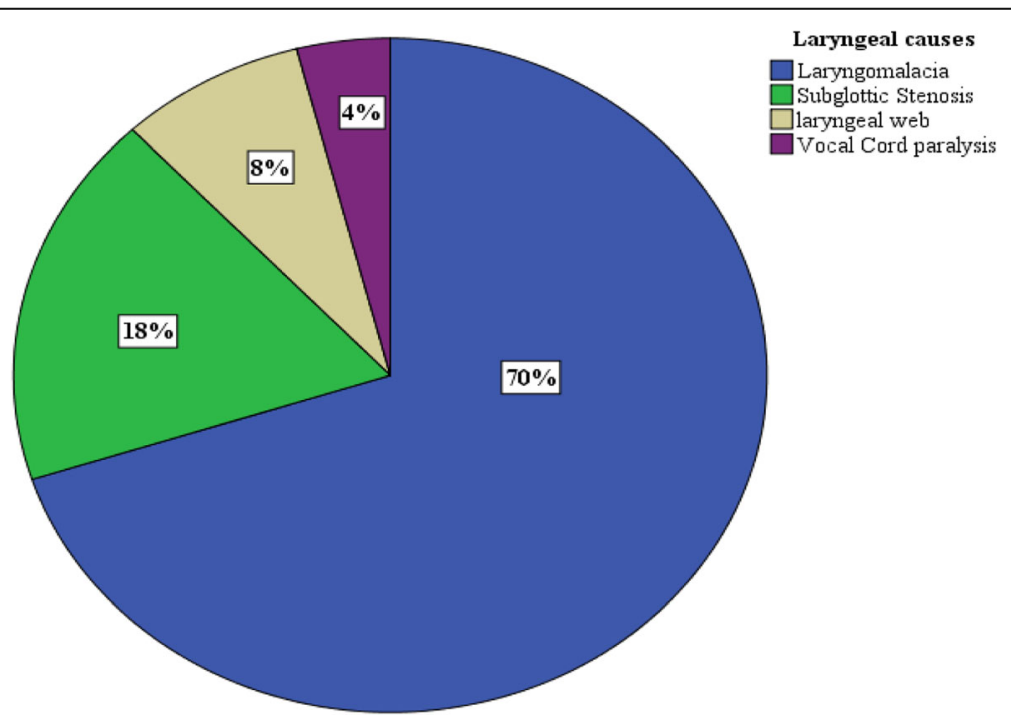

Fig. 2 Laryngeal causes of respiratory distress. This figure represents a pie chart for prevalence of different etiologies of the upper airway obstruction in infants. The laryngomalacia is the commonest cause (70\%) followed by subglottic stenosis (18\%) 
Table 1 Age distribution in different laryngeal causes of respiratory distress in infants

\begin{tabular}{|c|c|c|c|c|c|c|c|}
\hline \multirow[t]{2}{*}{ Laryngeal causes } & \multicolumn{2}{|c|}{$\begin{array}{l}1-6 \text { months } \\
(n=46)\end{array}$} & \multicolumn{2}{|l|}{$\begin{array}{l}6 \text { months to } 1 \text { year } \\
(n=23)\end{array}$} & \multicolumn{2}{|l|}{$\begin{array}{l}1 \text { year to } 2 \text { years } \\
(n=11)\end{array}$} & \multirow[t]{2}{*}{$P$ value } \\
\hline & No. & A.1.1.1.1.1.1.5. \% & A.1.1.1.1.1.1.4. No. & A.1.1.1.1.1.1.3. \% & A.1.1.1.1.1.1.2. No. & A.1.1.1.1.1.1.1.\% & \\
\hline Laryngomalacia & 36 & 78.4 & 16 & 69.5 & 4 & 36.4 & $(\mathrm{MCP}=0.257)$ \\
\hline Subglottic stenosis & 2 & 4.3 & 5 & 21.7 & 7 & 63.6 & \\
\hline Laryngeal web & 6 & 13 & 0 & 0 & 0 & 0 & \\
\hline Vocal fold paralysis & 2 & 4.3 & 2 & 8.8 & 0 & 0 & \\
\hline
\end{tabular}

MCP Monte Carlo exact $p$ value with confidence interval 95\%

laryngeal causes of respiratory distress. The majority of cases with laryngomalacia were male, 32 cases vs only 24 females. The same in subglottic stenosis cases, 10 males vs 4 females. There were 3 male cases versus 1 female who have vocal fold paralysis. Males and females were equal in cases of laryngeal web-3 cases for each (Table 2). In addition, there was no statistically significant difference in infants who had a positive family history vs those who had a negative family history $(\mathrm{MCP}=0.378)$. Only 8 cases with family history of the same conditions were detected, 6 cases had family history of laryngomalacia, and 2 cases had one family history of subglottic stenosis (Table 3). Other congenital anomalies were detected in 8 cases; five cases in laryngomalacia, 3 cases in subglottic stenosis and one case in patient with vocal fold paralysis as illustrated in Table 4.

\section{Discussion}

Respiratory disorders are the commonest causes of morbidity and mortality in the neonatal period [8]. It is an initial manifestation of a large number of respiratory or non-respiratory disorders like those of central nervous system origin, trauma, cardiac failure, or metabolic disorders. On autopsy, the incidence of respiratory disorders has been found to range from 32 to $54 \%$ [9]. In our study, the majority of cases (58\%) was between 1-6 months, followed by (28\%) cases between 6 months and 1 year, and only $14 \%$ between 1 year and 2 years. As regard sex, males constituted $60 \%$ of the study sample, while females were $40 \%$. The reason for the difference between the percentages of male and female patients presenting with stridor is unclear. This is in line with

Table 2 Distribution of sex among laryngeal causes of respiratory distress

\begin{tabular}{|c|c|c|c|c|c|}
\hline \multirow{2}{*}{$\begin{array}{l}\text { Laryngeal causes } \\
\text { Laryngomalacia }\end{array}$} & \multicolumn{2}{|c|}{$\begin{array}{l}\text { Male } \\
(n=48)\end{array}$} & \multicolumn{2}{|c|}{$\begin{array}{l}\text { Female } \\
(n=32)\end{array}$} & \multirow{2}{*}{$\begin{array}{l}p \text { value } \\
(M C P=0.286)\end{array}$} \\
\hline & 32 & 66.6 & 24 & 75 & \\
\hline Subglottic stenosis & 10 & 20 & 4 & 12.5 & \\
\hline Laryngeal web & 3 & 6.7 & 3 & 9.4 & \\
\hline Vocal fold paralysis & 3 & 6.7 & 1 & 3.1 & \\
\hline
\end{tabular}

MCP Monte Carlo exact $p$ value
Bjornson and Johnson, \& Denny et al., studies who reported that boys were affected more than girls (1.4:1) and young children between 6 months and 3 years of age more commonly than older children and adolescents $[10,11]$. Similarly, among the 81 laryngomalacia patients included in Olgun et al.'s study, 48 were male, and 33 were female, and the mean age was 4.9 months [12]. Also, among the total of 395 patients who were diagnosed with laryngomalacia and included in study by Irace et al., 92 (64.8\%) were males, with a median (interquartile range) age at the time of study of 7.9 (3.2-20.5) months [13]. Zoumalan et al., published a series of 202 infants under the age of 12 months examined for stridor in a specialized unit, 119 (59\%) were boys, and $83(41 \%)$ were girls. All patients were less than 1 year of age. Their ages ranged from 3 days to 11 months; 175 (87\%) were 6 months of age or younger [14]. In a similar study by Holinger, of 219 patients whose primary presenting symptom was stridor, 150 were male, and 69 were female [15]. In 324 children enrolled in Boogaard et al.'s study with laryngomalacia, 193 were males with a median (range) age of 4.4 (0 to 18) years [16]. A screening of 1986 consecutive live births done for the evidence of respiratory distress was included in the study by Nagendra et al. . Out of the 48 neonates who developed respiratory distress, 25 were males and 23 were females. The male-to-female ratio was $25: 23=1.08: 1$ [17]. A higher incidence in males was observed in the present study as well as in various earlier studies [17-19]. In the current study, the variables age, sex, family history, and

Table 3 Distribution of family history among laryngeal causes of respiratory distress

\begin{tabular}{|c|c|c|c|c|c|}
\hline \multirow[t]{4}{*}{ Laryngeal causes } & \multicolumn{4}{|c|}{ Family history } & \multirow[t]{4}{*}{$P$ Value } \\
\hline & \multirow{2}{*}{\multicolumn{2}{|c|}{$\begin{array}{l}\text { Positive } \\
(n=8)\end{array}$}} & \multirow{2}{*}{\multicolumn{2}{|c|}{$\frac{\text { Negative }}{(n=72)}$}} & \\
\hline & & & & & \\
\hline & No. & $\%$ & No. & $\%$ & \\
\hline Laryngomalacia & 6 & 76 & 50 & 69.4 & $(\mathrm{MCP}=0.378)$ \\
\hline Subglottic stenosis & 2 & 24 & 12 & 16.6 & \\
\hline Laryngeal web & 0 & 0 & 6 & 8.5 & \\
\hline Vocal fold paralysis & 0 & 0 & 4 & 5.5 & \\
\hline
\end{tabular}

MCP Monte Carlo exact $p$ value 
Table 4 Distribution of other congenital anomalies among laryngeal causes of respiratory distress

\begin{tabular}{llllll}
\hline Laryngeal causes & \multicolumn{3}{l}{ Other congenital anomalies } & \multirow{2}{*}{$p$ value } \\
\cline { 2 - 4 } & \multicolumn{2}{l}{$(n=8)$} & \multicolumn{2}{l}{$(n=72)$} & \\
\hline Laryngomalacia & 5 & 62.5 & 51 & 71 & (MCP = 0.222) \\
Subglottic stenosis & 2 & 25 & 12 & 16.6 & \\
Laryngeal web & 0 & 0 & 6 & 8.3 & \\
Vocal fold paralysis & 1 & 12.5 & 3 & 4.1 & \\
\hline
\end{tabular}

MCP Monte Carlo exact $p$ value

other congenital anomalies are not potent risk factors for developing laryngeal causes of respiratory distress. Moreover, in this study, we found the highest percentage of causes $(70 \%)$ were due to laryngomalacia, followed by subglottic stenosis (18\%) then laryngeal web (8\%), while vocal fold paralysis recorded the least percentage (4\%). This is consistent with Jabbour et al.'s study which included 404 patients with respiratory distress [20]. According to Escher et al. \& Thorne and Garetz's study, laryngomalacia is the most frequent cause of stridor in newborns and infants and is the underlying reason in 60 to $75 \%$ of cases with stridor [21,22]. In our study, only 5 cases of the 56 cases of laryngomalacia had other airway anomalies (9\%); this is in line with the Yuen et al., Rifai et al., \& Dickson et al. studies which reported that other airway pathologies can accompany laryngomalacia at rates varying from 7.5 to $64 \%$ [23-25]. Laryngomalacia is the most common cause of stridor in newborns, affecting $45-75 \%$ of all infants with congenital stridor according to Richter and Thompson [6]. Similarly, Daniel and Cheng reported that laryngomalacia is the commonest cause of neonatal stridor. Subglottic stenosis (SGS) is nowadays seen as relatively infrequent [26]. Thompson, reported that laryngomalacia (LM) is the most common laryngeal anomaly in infants [27]. The etiologies of airway obstruction in our subjects were laryngomalacia, subglottic stenosis, vocal fold paralysis, and laryngeal web. Our findings are consistent with Toews and Weiner who reported that laryngomalacia is the most prevalent cause of congenital stridor, accounting for $60 \%$ of cases [28]. However, unlike our results, they reported that congenital vocal fold paralysis is the next most common cause [19]. Similarly, Friedman et al. reported that laryngomalacia is the most common congenital anomaly of the larynx and is the most frequent cause of stridor in infants. It accounts for $60 \%$ of laryngeal problems in infants [29]. Other synchronous laryngotracheal anomalies have been reported by Berg and McClay, including subglottic stenosis and vocal fold paralysis [30]. Contrary to our study, Wolter et al. concluded that vocal fold paralysis (VFP) accounts for $10 \%$ of all congenital laryngeal anomalies and is the second most common cause next to laryngomalacia [31]. According to Zbar and Smith's results, laryngomalacia and subglottic stenosis most frequently affect infants, VFP is a common finding in both infants and adults [32]. The prevalence of associated airway lesions has been more clearly documented according to Mancuso et al; laryngeal dyskinesia, vocal fold paralysis, subglottic stenosis are more frequent in infants [33]. In this study, we found that subglottic stenosis represents the second most common cause of respiratory distress (18\%). This is inconsistent with some previous reports. Nicolai [34] and Shatla et al. [35] recorded that paralysis of the vocal folds is the second most common cause of neonatal stridor. Similar results were reported by Wiatrak, who founded that the second most common congenital anomaly of the larynx is vocal cord paralysis, accounting for $20 \%$ of laryngeal lesions [36]. This disagreement may be due to the limited number of subjects in our study. Also, the relatively difficult diagnosis of subglottic stenosis compared to more obviously seen diagnosis in the larynx could explain possible previous missing diagnosis. Among one hundred two cases of vocal fold paralysis (VFP), studied by Daya et al., most patients $(68 \%(n=69))$ were diagnosed before age 12 months; of these, $65 \%(n=45)$ presented with symptoms at birth [37]. In line with our study, Daniel's study reported that laryngomalacia is the most common congenital anomaly of the larynx. It represents $60 \%$ of all congenital laryngeal anomalies. Males are affected twice as often as females [38]. Laryngomalacia incidence was reported to be 1.6 times higher in boys than in girls according to Landry and Thompson's study [39]. Cukor and Manno found that laryngomalacia is the most common cause of chronic stridor in children younger than 2 years. It has a male-to-female ratio of approximately 2:1 [40]. Similarly, Jefferson et al. found in their study that congenital subglottic stenosis is the third most common congenital anomaly of the larynx. It accounts for $15 \%$ of all cases. Males are affected twice as often as females [41]. Schweiger et al. reported that the median age of the included children who developed subglottic stenosis was 2.6 months [42]. Cohen et al. [43] and Gentile et al. [44] also noted a marked male predominance. Among infants with idiopathic VFP (86\%). A total of 277 cases with VFP was studied by Gandhi et al., out of which 179 were males, and 98 were females with a male-to-female ratio being 1.82:1 [45]. Similar to the current study, Bedwell and Zalzal concluded that most cases of laryngomalacia occur sporadically in people with no family history of the condition [46]. On the other hand, Chen et al. reported that laryngomalacia may be inherited in some instances. Only a few cases of familial laryngomalacia (occurring in more than one family member) have been described in the literature [47]. Also, Gacek reported a family in which the father and two sons had hereditary bilateral vocal fold paralysis; another, 4 siblings, 1 male 
and 3 female, were normal. His patients also had other neurological findings later in life indicating possible association with the laryngeal defect [48].

\section{Limitation}

Every study has its own drawbacks. Our study has a limited number of cases; so, further research with a larger sample is recommended before generalization.

\section{Conclusion}

The highest percentage of respiratory distress (70\%) was due to laryngomalacia, followed by subglottic stenosis (18\%) then laryngeal web (8\%), while vocal fold paralysis was recorded with least percentage (4\%). The importance of determining the cause of stridor cannot be overemphasized, as the majority of infants presenting with stridor have laryngomalacia; however, there are numerous other possible etiologies to consider. Laryngomalacia is a common disease of infancy where the diagnosis is suspected by primary care providers based on history. Subglottic stenosis is the second most common etiology of stridor in our infants. This is important to suspect in order not to miss a relatively difficult and lifethreatening diagnosis. Recognizing patient factors and symptoms associated with moderate and severe diseases helps determine which infants will benefit from otolaryngology consultation. Identifying patient factors that influence disease severity and outcomes is an important aspect of counseling caregivers and providing care to infants.

\section{Abbreviations}

MSCT: Multi-slice computer tomography; VFP: Vocal fold paralysis

\section{Acknowledgements}

Not applicable

\begin{abstract}
Authors' contributions
HK has participated in data acquisition and interpretations and drafting of the manuscript. EE, BH, and AT diagnosed the cases and made the concept and design of the work and made major contributor in writing the manuscript. $\mathrm{EE}, \mathrm{BH}, \mathrm{MH}$, and $\mathrm{AT}$ participated in the analysis of data and interpretation of the results. $\mathrm{MH}$ was a major contributor in writing the manuscript and made intelligible revision of the text. The authors read and approved the final manuscript.
\end{abstract}

\section{Funding}

None.

\section{Availability of data and material}

The datasets used and/or analyzed during the current study are available from the corresponding author on reasonable request.

\section{Ethics approval and consent to participate}

The current research was approved by the Institutional Ethical Committee of the Faculty of Medicine, Aswan University (EC Ref No: aswu/456/5/20). Also, written informed consents were obtained from all parents to participate in the research.

\section{Consent for publication}

Written informed consents for publication were obtained from all parents.

\section{Competing interests}

The authors declare that they have no competing interests.

\begin{abstract}
Author details
${ }^{1}$ Otolaryngology Department, Faculty of Medicine, Aswan University, Aswan, Egypt. ${ }^{2}$ Pediatric Department, Faculty of Medicine, Aswan University, Aswan, Egypt. ${ }^{3}$ Phoniatrics Unit, Otolaryngology Department, Faculty of Medicine, Sohag University, Sohag, Egypt.
\end{abstract}

Received: 9 May 2020 Accepted: 25 August 2020

Published online: 07 October 2020

\section{References}

1. Wine TM, Dedhia K, Chi DH (2014) Congenital nasal pyriform aperture stenosis: is there a role for nasal dilation? JAMA Otolaryngol Head Neck Surg 140(4):352-356

2. Ayari S, Aubertin G, Girschig H, Van Den Abbeele T, Mondain M (2012) Pathophysiology and diagnostic approach to laryngomalacia in infants. Eur Ann Otorhinolaryngol Head Neck Dis 129(5):257-263

3. Evans KN, Sie KC, Hopper RA, Glass RP, Hing AV, Cunningham ML (2011) Robin sequence: from diagnosis to development of an effective management plan. Pediatrics 127(5):936-948

4. Dobbie AM, White D (2013) Laryngomalacia. Pediatr Clin N Am 60(4):893902

5. Qandalji B (2010) Full term neonatal admissions. Early Human Development Conference 86(pp S133):S133

6. Richter GT, Thompson DM (2008) The surgical management of laryngomalacia. Otolaryngol Clin N Am 41(5):837-864

7. Mathur NB, Garg K, Kumar S (2002) Respiratory distress in neonates with special reference to pneumonia. Indian Pediatr 39:529-537

8. Kusak B, Cichocka-Jarosz E, Jedynak-Wasowicz U, Lis G (2017) Types of laryngomalacia in children: interrelationship between clinical course and comorbid conditions. European archives of oto-rhino- laryngology: official journal of the European Federation of Oto- Rhino-Laryngological Societies (EUFOS): affiliated with the German Society for Oto-Rhino-Laryngology Head and Neck. Surgery 274:1577-1583

9. Landry AM, Thompson DM (2012) Laryngomalacia: disease presentation, spectrum and management. Int J Pediatr 2012:6

10. Bjornson CL, Johnson DW (2013) Croup in children. Cmaj 185:1317-1323

11. Denny FW, Murphy TF, Clyde WA, Collier AM, Henderson FW, Senior R et al (1983) Croup: an 11-year study in a pediatric practice. Pediatrics 71:871-876

12. Olgun Y, Özay H, Çakır A, Erdağ TK (2016) Laryngomalacia: our clinical experience. Turk Arch Otorhinolaryngol 54:150-153

13. Irace AL, Dombrowski ND, Kawai K, Watters K, Choi S, Perez J et al (2019) Evaluation of aspiration in infants with laryngomalacia and recurrent respiratory and feeding difficulties. JAMA Otolaryngol Head Neck Surg 145(2):146-151

14. Zoumalan R, Maddalozzo J, Holinger LD (2007) Etiology of stridor in infants. Ann Otol Rhinol Laryngol 116(5):329-334

15. Holinger LD (1980) Etiology of stridor in the neonate, infant and child. Ann Otol Rhinol Laryngol 89:397-400

16. Boogaard R, Huijsmans SH, Pijnenburg MW, Tiddens HA, de Jongste JC, Merkus PJ (2005) Tracheomalacia and bronchomalacia in children: incidence and patient characteristics. Chest 128:3391-3397

17. Nagendra K, Wilson CG, Ravichander B, Sood SM, Singh SP (1999) Incidence and etiology of respiratory distress in newborn. Med J Armed Forces India 55:331-333

18. Kumar A, Bhat BV (1996) Epidemiology of respiratory distress of newborns. Indian J Pediatr 63:93-98

19. Driscoll SG, Smith CA (1962) Neonatal pulmonary disorders. Pediatr Clin N Am 9:325-352

20. Jabbour J, Martin T, Beste D, Robey T (2014) Pediatric vocal fold immobility: natural history and the need for long-term follow-up pediatric vocal fold immobility. JAMA Otolaryngol Head Neck Surg 140:428-433

21. Escher A, Probst R, Gysin C (2015) Management of laryngomalacia in children with congenital syndrome: the role of supraglottoplasty. J Pediatr Surg 50:519-523

22. Thorne MC, Garetz SL (2016) Laryngomalacia: review and summary of current clinical practice in 2015. Paediatr Respir Rev 17:3-8 
23. Yuen H-W, Tan HK-K, Balakrishnan A (2006) Synchronous airway lesions and associated anomalies in children with laryngomalacia evaluated with rigid endoscopy. Int J Pediatr Otorhinolaryngol 70:1779-1784

24. Rifai HA, Benoit M, El-Hakim H (2011) Secondary airway lesions in laryngomalacia: a different perspective. Otolaryngol Head Neck Surg 144: 268-273

25. Dickson JM, Richter GT, Meinzen-Derr J, Rutter MJ, Thompson DM (2009) Secondary airway lesions in infants with laryngomalacia. Ann Otol Rhinol Laryngol 118:37-43

26. Daniel M, Cheng A (2012) Neonatal stridor. Int J Pediatr 2012(Article ID 859104):5

27. Thompson DM (2007) Abnormal sensorimotor integrative function of the larynx in congenital laryngomalacia: a new theory of etiology. Laryngoscope 117:1-33

28. Toews J, Weiner EJ (2017) Stridor in the infant and young child. Emerg Med Rep 38

29. Friedman EM, Vastola AP, Mcgill TJ, Healy GB (1990) Chronic pediatric stridor: etiology and outcome. Laryngoscope 100:277-280

30. Berg EE, McClay J (2015) Tracheobronchomalacia. In: Disorders of the neonatal airway. Springer, pp 87-95

31. Wolter NE, Ayele N, Kawai K, Hseu A, Nuss R (2019) Medialization laryngoplasty in pediatric patients with unilateral vocal fold immobility: a case series. Ann Otol Rhinol Laryngol 128:145-151

32. Zbar RIS, Smith RJH (1996) Vocal fold paralysis in infants twelve months of age and younger. Otolaryngol Head Neck Surg 114:18-21

33. Mancuso RF, Choi SS, Zalzal GH, Grundfast KM (1996) Laryngomalacia: the search for the second lesion. Arch Otolaryngol Head Neck Surg 122:302-306

34. Nicolai T (2001) Pediatric bronchoscopy. Pediatr Pulmonol 31:150-164

35. Shatla ES, Prashanth GP, Aguiar R, Shivalingam G, Al Haq AA (2017) Neonatal stridor in familial congenital laryngeal paralysis (plott syndrome): a case study in an Omani family. Oman Med J 32:515-517

36. Wiatrak BJ (2000) Congenital anomalies of the larynx and trachea. Otolaryngol Clin N Am 33:91-110

37. Daya H, Hosni A, Bejar-Solar I, Evans JNG, Bailey CM (2000) Pediatric vocal fold paralysis: a long-term retrospective study. Arch Otolaryngol Head Neck Surg 126:21-25

38. Daniel SJ (2006) The upper airway: congenital malformations. Paediatr Respir Rev 7:S260-S263

39. Landry A, Thompson DM (2015) Congenital laryngomalacia: disease spectrum and management. In: Disorders of the neonatal airway. Springer, pp 51-57

40. Cukor J, Manno M (2010) Pediatric respiratory emergencies. In: Rosen's emergency medicine: concepts and clinical practice, 7th ed, Mosby, Inc. chapter 166

41. Jefferson ND, Cohen AP, Rutter MJ (2016) Subglottic stenosis. In: Seminars in pediatric surgery. Elsevier, pp 138-143

42. Schweiger C, Manica D, Pereira DRR, Carvalho PRA, Piva JP, Kuhl G et al (2017) Undersedation is a risk factor for the development of subglottic stenosis in intubated children. J Pediatr 93:351-355

43. Cohen SR, Geller KA, Birns JW, Thompson JW (1982) Laryngeal paralysis in children: a long-term retrospective study. Ann Otol Rhinol Laryngol 91:417424

44. Gentile RD, Miller RH, Woodson GE (1986) Vocal cord paralysis in children 1 year of age and younger. Ann Otol Rhinol Laryngol 95:622-625

45. Gandhi S, Rai S, Bhowmick N (2014) Etiological profile of unilateral vocal cord paralysis: a single institutional experience over 10 years. J Laryngol Voice 4:58-62

46. Bedwell J, Zalzal G (2016) Laryngomalacia. In: Seminars in pediatric surgery Elsevier, pp 119-122

47. Chen JL, Messner AH, Chang KW (2006) Familial laryngomalacia in two siblings with syndromic features. Int J Pediatr Otorhinolaryngol 70:16511655

48. Gacek RR (1976) Hereditary abductor vocal cord paralysis. Ann Otol Rhinol Laryngol 85:90-93

\section{Publisher's Note}

Springer Nature remains neutral with regard to jurisdictional claims in published maps and institutional affiliations.

\section{Submit your manuscript to a SpringerOpen ${ }^{\circ}$ journal and benefit from:}

- Convenient online submission

- Rigorous peer review

- Open access: articles freely available online

- High visibility within the field

- Retaining the copyright to your article

Submit your next manuscript at $\boldsymbol{\nabla}$ springeropen.com 